\title{
Exploring Efficacy of a Serious Game (TOBBSTOP) for Smoking Cessation in Pregnant Women: Pilot Case-Control Study
}

Francesc X Marin-Gomez ${ }^{1,2,3}$, MD; Rosada Garcia-Moreno ${ }^{4}, \mathrm{MD}$; Anabel Mayos-Fernandez ${ }^{4}$, MSN; Cristina Rey-Reñones ${ }^{5,6}$, DNP

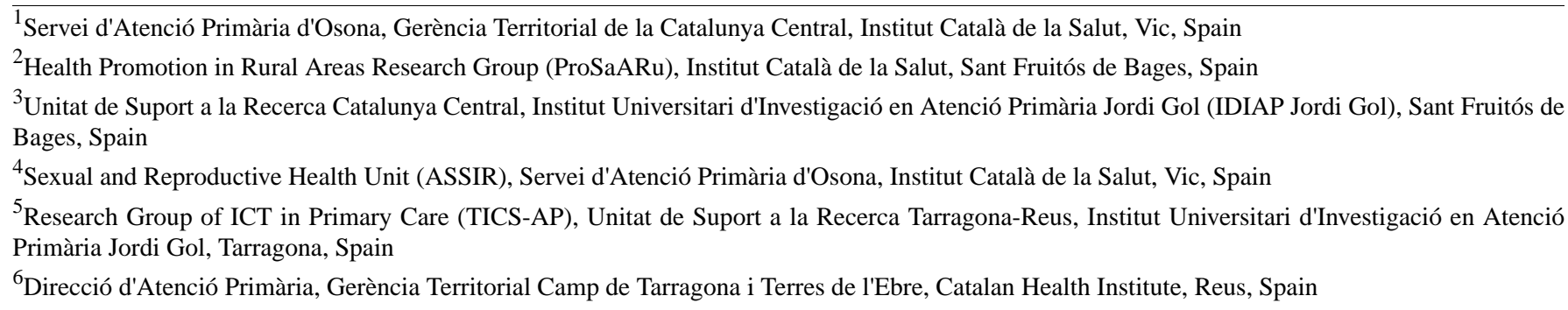

Corresponding Author:

Francesc X Marin-Gomez, MD

Servei d'Atenció Primària d'Osona

Gerència Territorial de la Catalunya Central

Institut Català de la Salut

Pl Divina Pastora, 7

Vic, 08500

Spain

Phone: 34938890222

Email: xmarin.cc.ics@gencat.cat

\begin{abstract}
Background: Tobacco use entails, during pregnancy, a serious risk to the mother and harmful effects on the development of the child. Europa has the highest tobacco smoking prevalence (19.3\%) as compared to a worldwide mean of $6.8 \%$. Twenty to thirty percent of pregnant women used tobacco during pregnancy worldwide. These data emphasize the urgent need for community education and implementation of prevention strategies focused on risks associated to tobacco use during pregnancy.

Objective: This study aims to investigate the possibility to address this problem through a serious game (TOBBSTOP), something that has proven efficient as a tool for learning in many situations. By using a game for smoke cessation during pregnancy, we aim to maintain cessation and interest pregnant smokers in learning about health care and effects of tobacco by playing a game that helps them to achieve their challenge.

Methods: A pilot case-control study enrolls 44 women who were visited in two primary care centers in Spain between March 2015 and November 2016. All participants were pregnant smokers over the age of 17 years attending consultation to a midwife during the first trimester of pregnancy who expressed their desire to stop smoking. We recruited the intervention group $(\mathrm{n}=22)$ among the attended on the centers and instructed them to install the game on their smartphone or tablet and use it for 3 months. Until the delivery, all participants had to respond to a questionnaire, assessing their stage on smoke cessation during their follow-up midwife consultations. The selected control group participants $(\mathrm{n}=22)$, matched for age, level of tobacco-dependence and number of smoking attempts. We tested the amount of $\mathrm{CO}$ at each visit with a carboxymeter during the entire intervention period to assess the abstinence.
\end{abstract}

Results: Pregnant women from the intervention group, with $80.0 \%$ (12/15), had significant higher rates of cessation until delivery than control group $\left(\chi^{2}=8.4 ; P=.004\right)$. Logistic regression analyses revealed that game's use was associated with an increased likelihood to maintain smoking cessation during the intervention period compared with those not using the game (odds ratio 4.0; 95\% CI 1.3-12.2). Additionally, a Mantel-Cox means' analysis revealed that the use of the game was associated with an increased number of days without smoking, with an average of 139.7 days (95\% CI 97.1-182.4) in the intervention group $\left(\chi^{2}=13.912\right.$; $P<.001)$.

Conclusions: Pregnancy is an ideal opportunity to intervene and control tobacco use among future mothers. On the other hand, serious games is an emerging technology, growing in importance, which is shown as a good tool to assist in maintaining women 
without smoking and help behavior change during pregnancy. However, due to study design limitations, these outcomes should be interpreted with caution. More research, using larger samples and longer follow-up periods, is needed to replicate the findings of this study.

(iproc 2018;4(2):e11878) doi: $\underline{10.2196 / 11878}$

\section{KEYWORDS}

pregnancy; serious games; smoking cessation

\section{Multimedia Appendix 1}

Full poster.

[PDF File (Adobe PDF File), 1MB-Multimedia Appendix 1]

Edited by T Hale; this is a non-peer-reviewed article. Submitted 08.08.18; accepted 29.08.18; published 17.09.18.

Please cite as:

Marin-Gomez FX, Garcia-Moreno R, Mayos-Fernandez A, Rey-Reñones $C$

Exploring Efficacy of a Serious Game (TOBBSTOP) for Smoking Cessation in Pregnant Women: Pilot Case-Control Study iproc 2018;4(2):e11878

URL: http://www.iproc.org/2018/2/e11878/

doi: $\underline{10.2196 / 11878}$

PMID:

CFrancesc X Marin-Gomez, Rosada Garcia-Moreno, Anabel Mayos-Fernandez, Cristina Rey-Reñones. Originally published in Iproceedings (http://www.iproc.org), 17.09.2018. This is an open-access article distributed under the terms of the Creative Commons Attribution License (https://creativecommons.org/licenses/by/4.0/), which permits unrestricted use, distribution, and reproduction in any medium, provided the original work, first published in Iproceedings, is properly cited. The complete bibliographic information, a link to the original publication on http://www.iproc.org/, as well as this copyright and license information must be included. 